\title{
A Short Review of Factors and Interventions for Reducing Depression
}

\section{Stoyanova $S^{*}$}

Department of Psychology, South-West University “Neofit Rilski”, Bulgaria

*Corresponding author: Stanislava Yordanova Stoyanova, South-West University

“Neofit Rilski”, 66, Ivan Mihailov Str., 2700 Blagoevgrad, Bulgaria, Tel: 00359888846816; E-mail: avka@abv.bg

\section{Mini Review \\ Volume 1 Issue 1}

Received Date: July 19, 2017

Published Date: August 10, 2017

DOI: $10.23880 / \mathrm{mhrij}-16000104$

\section{Abstract}

This short review of some factors and interventions for reducing depression is focused on the role of multiple agents and activities in different kinds of relationships and various types of environment. It aims to reveal the complex co-action of such factors, not to point out the primary importance of one or few of them. Some research findings regarding the efficiency of some psychotherapeutic, school, family, community and activity-focused interventions for recovery from depression are described and summarized.

Keywords: Depression; Intervention; Recovery

\section{Introduction}

Early diagnostics and detection of depression is important for facilitating treatment efforts for many kinds of illnesses, because it has been found that depression comorbidity diminishes longevity in the case of some somatic diseases [1]. Screening for depression could help children and adolescents benefit from care by mental health specialists [2]. Satisfactory communication of doctors and other mental health specialists with patients and their relatives could contribute to diminished levels of depression [3], so its improvement is important.

Medical staff's good communication skills contribute to placebo effect for treatment of depression creating a positive attitude in patients. It has been established that taking pill placebo is effective in treatment of depression, almost as well as taking antidepressants [4-6]. Placebo effect for successful treatment of depression could be explained by hope and the expectations of improvement, belief in given support by an expert, and a healing ritual
[4,5]. Cross-over research design (the same patients received both medication and placebo at different time periods) also indicated the efficacy of placebo treatment for depression, not only of antidepressants [7-9], as the studies with a parallel control group receiving placebo did $[6,8]$.

Treatment of depression is complex. It includes some medicines, psychotherapy, training, and the possible changes of the way of life and the environment $[10,11]$.

Even Aromatherapy has been applied for diminishing depressive symptoms and it has been found that some flower essences (such as Chestnut, Chicory, and Wild Rose) may facilitate recovery of mild depression [12].

Different types of psychotherapy could be effective for recovering depression - individual and group therapy, Cognitive Behavioural therapy, music therapy, relaxation 


\section{Mental Health \& Human Resilience International Journal}

training, school and family focused interventions such as increasing knowledge about depression, providing family support, etc. $[10,13]$.

Cognitive Behavioural Therapy (CBT) is effective for treatment of depression [14-16]. Some studies have been focused on comparing CBT and other therapies, and superiority of CBT has been proved, is evident for depressive disorders [17].

The group music therapy, rhythm and movement training, relaxation training and painting training are effective for diminishing depression [18]. Active group inclusion, talk and sharing diminish the levels of depression [15] that could be efficiently practiced in the school environment.

School-focused interventions may be more effective for boys; family-focused interventions may be more beneficial for girls for diminishing depression [19]. A 3hour curriculum to teach high school students about the illness of depression was effective on increasing their knowledge about depression and decreasing morbidity, mortality, and stigma associated with adolescent depression [20].

Improving cognitive functioning (information processing speed, attention control, short term memory, learning and cognitive planning, sensory discrimination) is important for diminishing the negative effects from depression [21,22]. Self-expression by means of overt and assertive behaviour, as well as self-realization give the possibilities for students' improved cognitive functioning in the academic environment [23], and aesthetic experiences in the learning process also contribute to positive emotions and further development of cognitive functioning by means of complex processing of information [24].

Negative emotional states, including depression, could be reduced by means of improving satisfaction from the learning process and from the relationships between the participants in the learning process [25]. Interventions focused on diminishing anxiety, neuroticism (for example by meeting one's expectancies) and psychoticism (developing empathy and altruism), as well as on increasing extraversion (better communication, social support) could be effective for diminishing depression throughout the whole school year [13]. Motivating students, participating in more extra-curriculum activities related to students' plans for further realisation in universities and workplace would be useful for diminishing students' depression [13]. Positive reappraisal and planning are related with low levels of depression [26].

Spending time on preferred activities could enhance positive emotions and diminish depression [13], especially self-chosen activities whose proportion varies cross-culturally [27]. Moderate physical activity and exercise are important in preventing depression [28,29]. Sports practice could reduce negative emotional states [30].

Active civic participation increases the interest in communication with diverse individuals, groups and communities that may improve the relationships and emotional state [31]. Internet use (using social networks and instant messaging) is associated with decreased levels of depression in adolescents [32]. Social identities and social identification provide meaning to life, encourage the provision and receipt of social support, facilitate positive social influence, and engender a sense of belongingness and community that all protect against depression [33].

Positive parent-adolescent relationships provoke more positive self-assessment in adolescents and reduce the risk of adolescents' depression [34]. Decrease of mothers' rumination and increase of mothers' forgiveness can be efficient in diminishing adolescents' depression [35]. One of the protective factors for depression is social support [36].

Improving emotion recognition and social functioning (romantic relationships, communication, motivation, and social support) could diminish depression [37-39]. Prevention of depression is assisted by means of enhancing self-esteem, independence and autonomy in making one's choices [13]. Higher self-esteem negatively correlated with depression [40].

There are different possibilities for diminishing depression. Different factors have been described that may complement each other for diminishing depression. Besides, Mental Health \& Human Resilience International Journal (MHRIJ) gives the possibility for disseminating useful scientific information regarding mental diseases increasing in such a way human resilience against such diseases and contributing to good mental health condition. 


\section{Mental Health \& Human Resilience International Journal}

\section{References}

1. Thomson W (2014) The head stands accused by the heart! -Depression and premature death from ischaemic heart disease. Open Journal of Depression 3(2): 33-40.

2. Allison VL, Nativio DG, Mitchell AM, Ren D, Yuhasz J (2014) Identifying symptoms of depression and anxiety in students in the school setting. J Sch Nurs 30(3): 165-172.

3. Giannouli V,Stoyanova S (2014) Does Depressive Symptomatology Influence Teenage Patients and Their Mothers' Experience of Doctor-Patient Relationship in Two Balkan Countries?. Psychological Thought 7(1): 19-27.

4. Brown WA (1994) Placebo as a treatment for depression. Neuropsychopharmacology 10(4): 265269.

5. Sonawalla SB, Rosenbaum JF (2002) Placebo response in depression. Dialogues Clin Neurosci 4(1): 105-113.

6. Walsh BT, Seidman SN, Sysko R, Gould M (2002) Placebo response in studies of major depression variable, substantial, and growing. JAMA 287(14): 1840-1847.

7. Elfhag K, Rössner S (2005) Short-term difference in mood with sibutramine versus placebo in obese patients with and without depression. Therapy 2(1): 107-112.

8. Ibrahim L, Diaz Granados N, Jolkovsky L, Brutsche N, Luckenbaugh DA, et al. (2012) A Randomized, Placebo-Controlled, Crossover Pilot Trial of the Oral Selective NR2B Antagonist MK-0657 in Patients With Treatment-Resistant Major Depressive Disorder. J Clin Psychopharmacol 32(4): 551-557.

9. Patkar AA, Pae CU, Vöhringer PA, Mauer S, Narasimhan M, et al. (2015) A 13-week, randomized double-blind, placebo-controlled, cross-over trial of ziprasidone in bipolar spectrum disorder. J Clin Psychopharmacol 35(3): 319-323.

10. Ivanova D (2015) Konsultirane I psihoterapianasazavisimostta [Consultation and psychotherapy of co-dependency]. Blagoevgrad, Bulgaria: South-West University "NeofitRilski".
11. Stoyanova S (2014) Depression-Factors, Symptoms, Prevention and the Role of Open Journal of Depression. Open Journal of Depression3(1): 3-4.

12. Cram JR, Silva PS, González EHR, de la Llera M, de los ÁF, et al. (2005) Five clinical studies demonstrate the effectiveness of flower essence therapy in the treatment of depression. A Convergence of evidence: Flower essence therapy in the treatment of Major Depression. Calix 1: 89-106.

13. Stoyanova S, Petrova V (2015) Dynamics of depression among adolescents in secondary schools in Bulgaria. Problems of Psychology in the 21st century 9(1): 26-44.

14. Butler AC, Chapman JE, Forman EM, Beck AT (2006) The empirical status of cognitive-behavioral therapy: A review of meta-analyses. Clinical Psychology Review 26(1): 17-31.

15. Dobson KS, Hopkins JA, Fata L, Scherrer M, Allan LC (2010) The prevention of depression and anxiety in a sample of high-risk adolescents: A randomized controlled trial. Canadian Journal of School Psychology 25(4): 291-310.

16. Iddon JL, Grant L (2013) Behavioural and cognitive treatment interventions in depression: an analysis of the evidence base. Open Journal of Depression 2(2): 11-15.

17. Tolin DF (2010) Is cognitive-behavioral therapy more effective than other therapies? A meta-analytic review. Clini Psychol Rev 30(6): 710-720.

18. Wang J, Wang H, Zhang D (2011) Impact of group music therapy on the depression mood of college students. Health 3(3): 151-155.

19. Lee G, McCreary L, Kim MJ, Park CG, Jun WH, et al. (2012) Depression in low-income elementary school children in South Korea: Gender differences. Journal of School Nursing 29(2): 132-141.

20. Swartz KL, Kastelic EA, Hess SG, Cox TS, Gonzales LC, et al. (2010) The effectiveness of a school-based adolescent depression education program. Health EducBehav 37(1): 11-22.

21. Korsnes MS, Ulstein ID (2014) Cognitive effects of late life depression: Review of neuropsychological findings. Journal of Behavioral and Brain Science 4(3): 141-157. 


\section{Mental Health \& Human Resilience International Journal}

22. Nogueira RMTBL, Espínola EL, Lacerda AM, Santos NA (2006) Mesopic Visual Contrast Sensitivity in Patients with Major Depression. Open Journal of depression 2(4): 82-86.

23. Mutafova M (2015) Vaprosinavazrastovata I pedagogicheskatapsihologia [Questions of Developmental and Educational Psychology]. Blagoevgrad, Bulgaria: South-West University "NeofitRilski".

24. Yordanova B (2016) Psihologianaesteticheskotoprejiviavane [Psychology of aesthetic experiences]. Blagoevgrad, Bulgaria: South-West University "NeofitRilski".

25. Stoyanova S, Yovkov L (2016) Educational Objectives in E-Learning. International Journal of Humanities Social Sciences and Education 3(9): 8-11.

26. Omran MP (2011) Relationships between cognitive emotion regulation strategies with depression and anxiety. Open Journal of Psychiatry 1(3): 106-109.

27. Newman J, Bidjerano T, Özdog ru AA, Kao CC, ÖzköseBiyik C, et al. (2007) What do they usually do after school? A comparative analysis of fourth-grade children in Bulgaria, Taiwan, and the United States. Journal of Early Adolescence 27(4): 431-456.

28. Gavric Z (2012) Determining the score for depression and its relationship with the level of physical activity in a patient at the family medicine. Open Journal of Depression 1(1): 1-7.

29. Guida J, Sundaram S, Leiferman J (2012) Antenatal physical activity: Investigating the effects on postpartum depression. Health 4(12): 1276-1286.

30. Ivantchev N, Yordanov S (2014) Specifics of the psyhologicaldefense of those learning the combat sports. Psychological Thought 7(2): 179-186.

31. Zografova Y (2016) Diversity from social psychological perspective. Sofia, Bulgaria: MIV Consult Ltd.
32. Thorsteinsson EB, Davey L (2014) Adolescents' Compulsive Internet use and depression: A longitudinal study. Open Journal of depression 3(1): 13-17.

33. Cruwys T, Haslam SA, Dingle GA, Haslam C, Jetten J (2014) Depression and social identity: An integrative review. Personality and Social Psychology Review 18(3): 215-238.

34. Hu J, Ai H (2014) Self-esteem mediates the effect of the parent-adolescent relationship on depression. Journal of Health Psychology 21(6): 897-904.

35. Jafari F, Yousefi Z, Manshaee GR (2014) Mothers characters and adolescence depression. Open Journal of Depression 3(2): 45-51.

36. Thorsteinsson E, Ryan SM, Sveinbjornsdottir S (2013) The mediating effects of social support and coping on the stress-depression relationship in rural and urban adolescents. Open Journal of Depression 2(1): 1-6.

37. Gulamani SS, Premji SS, Kanji Z, Azam SI (2008) Preterm Birth a Risk Factor for Postpartum Depression in Pakistani Women. Open Journal of Depression 2(4): 72-81.

38. Ille R, Hofmann P, Ebner C, Kapfhammer HP, Schienle A (2005) Mood-related negative bias in response to affective stimuli in patients with major depression. Open Journal of Depression 2(4): 64-71.

39. Sharabi LL, Delaney AL, Knobloch LK (2015) In their own words: How clinical depression affects romantic relationships. Journal of Social and Personal Relationships 33(4): 421-448.

40. Yu X, FanG (2014) Direct and indirect relationship between locus of control and depression. J Health Psychol 21(7): 1293-1298.

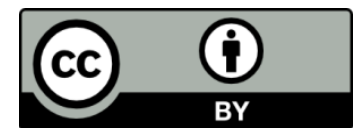

